\title{
A woman with a maple leaf in her abdomen
}

A n 82-year-old woman who had immigrated to Canada 40 years previously, after escaping Nazi persecution in the Second World War and living in the Netherlands for 20 years, was admitted to our General Internal Medicine ward with aspiration pneumonitis. Her medical history was significant for esophageal dysmotility, coronary artery disease, hypertension, Crohn's disease and an antecedent pulmonary embolus (PE). During her hospital stay, her inflammatory bowel disease worsened, warranting radiological investigation. While examining the CT scan of her abdomen, we were surprised to note a foreign body in her abdomen that appeared to have the shape of a star, or possibly a large maple leaf (Fig. 1). Four years earlier, the patient had had deep vein thrombosis and $\mathrm{PE}$ coincident with a rectus sheath hematoma, a peptic ulcer and a heightened risk for falls. It was decided at the time that anticoagulation was contraindicated, and a Greenfield inferior vena cava (IVC) filter was placed to prevent the formation of PEs.

Anticoagulation with unfractionated heparin, low-molecularweight heparin or warfarin is considered the first line of treatment of proximal deep vein thrombosis and prevention of pulmonary embolism. ${ }^{1}$ However, + certain comorbid medical conditions - including active visceral hemorrhage, recent cerebral or meningeal bleeds, recent head trauma or neurosurgery - and the concomitant need for major surgery preclude the use of anticoagulation in some patients. In

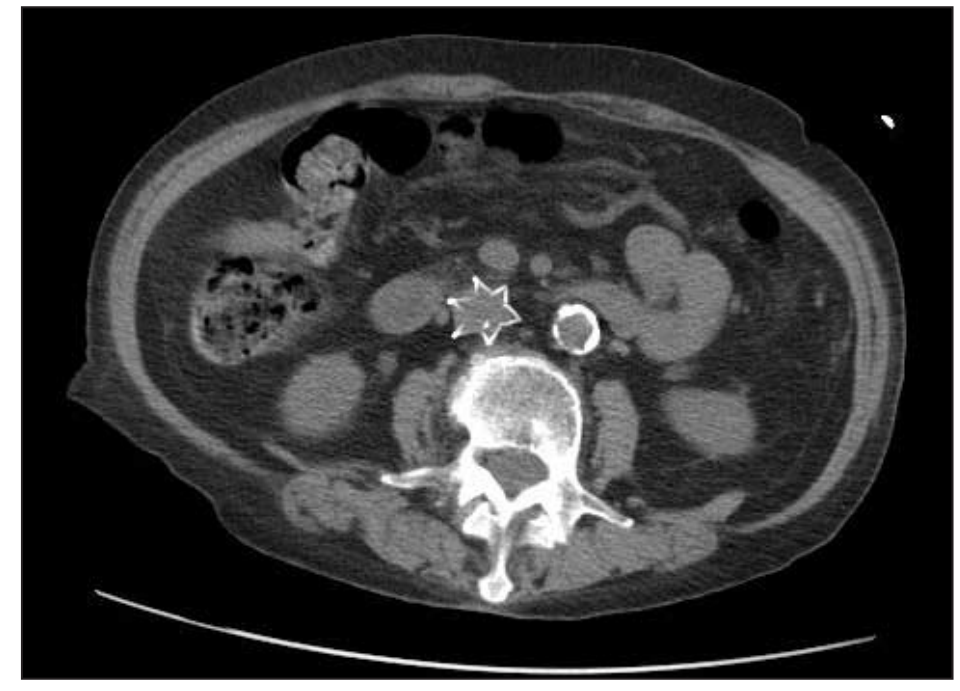

such patients and those who fail anticoagulation (as documented by the propagation of a clot or the development of a PE despite adequate medical therapy) an IVC filter is sometimes used. ${ }^{2}$ These filters, inserted percutaneously through the femoral or jugular veins, trap migrating thrombi before they can cause a PE. ${ }^{3}$

The evidence supporting the efficacy of IVC filters is limited. In 1 randomized controlled trial lasting 2 years, the incidence of $\mathrm{PE}$ in patients fitted with a filter was less than in those without a filter, but, overall, there was no significant difference in mortality between the 2 groups. ${ }^{4}$ Both groups received anticoagulation treatment with either unfractionated or low-molecular-weight heparin during the first 8-10 days of the trial, and warfarin for 3 months after the initiation of treatment. Furthermore, the same study showed that patients with a filter seemed to have an increased rate of deep vein thrombosis. This suggests that even patients with IVC filters should be considered for concur- rent anticoagulation if at all possible. Despite these shortcomings, IVC filters are widely used, and their distinct radiologic appearance is not only intriguing but important to recognize.

\section{Olivia Bottenheim}

Medical student

McGill University

Kenneth M. Flegel

Department of Medicine

Robert Hanson

Department of Radiology

McGill University Health Centre

Montréal, Que.

\section{References}

1. Pineo G, Mant M, Robinson S, Wells P. Practical treatment guidelines: initial treatment of venous thromboembolism. The Thrombosis Interest Group of Canada; 2002. Available: www.tigc.org/eguidelines/lmwh02.htm (accessed 2004 May 12).

2. Girard P, Tardy B, Decousus H. Inferior vena cava interruption: how and when? Ann Rev Med 2000;51:1-15.

3. Kinney, T. Update on inferior vena cava filters. 7 Vasc Interv Radiol 2000; 14:425-40. Page Y, Tardy B, Girard P, et al. A clinical trial of vena cava filters in the prevention of pulmonary embolism in patients with proximal deep-vein thrombosis. NEngl f Med 1998;338(7): 409-15.
4. Decousus H, Leizorovicz A, Parent F, 